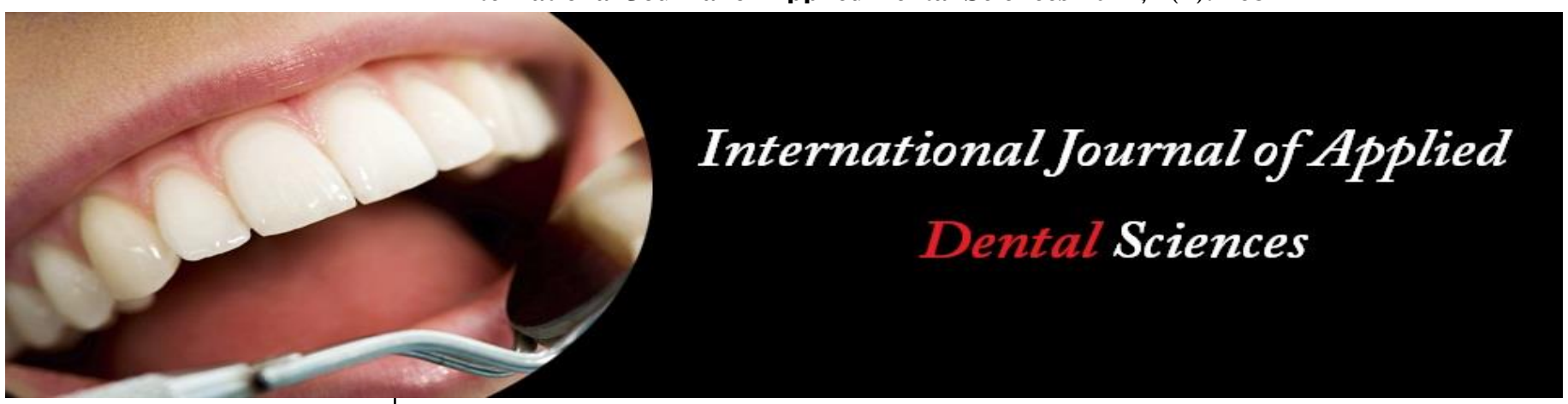

ISSN Print: 2394-7489

ISSN Online: 2394-7497

IJADS 2021; 7(1): 468-471

(C) 2021 IJADS

www.oraljournal.com

Received: 07-11-2020

Accepted: 09-12-2020

Dr. Anil K Tomer

Professor and Head, Department of

Conservative Dentistry and

Endodontics, Divya Jyoti College of

Dental Sciences and Research,

Modinagar, Uttar Pradesh, India

Dr. Lungdin Leima Cecilia

Postgraduate Students, Department

of Conservative Dentistry and

Endodontics, Divya Jyoti College of

Dental Sciences and Research,

Modinagar, Uttar Pradesh, India

Dr. Hysum Mushtaq

Postgraduate Students, Department of Conservative Dentistry and

Endodontics, Divya Jyoti College of

Dental Sciences and Research,

Modinagar, Uttar Pradesh, India

Dr. Ayush Tyagi

Postgraduate Students, Department of Conservative Dentistry and

Endodontics, Divya Jyoti College of Dental Sciences and Research,

Modinagar, Uttar Pradesh, India

Dr. Shivendra Ahlawat

Postgraduate Students, Department of Conservative Dentistry and

Endodontics, Divya Jyoti College of

Dental Sciences and Research,

Modinagar, Uttar Pradesh, India

Dr. Tony Jose

Postgraduate Students, Department of Conservative Dentistry and

Endodontics, Divya Jyoti College of

Dental Sciences and Research,

Modinagar, Uttar Pradesh, India

Dr. Ayushi Khandelwal

Postgraduate Students, Department of Conservative Dentistry and

Endodontics, Divya Jyoti College of

Dental Sciences and Research,

Modinagar, Uttar Pradesh, India

Corresponding Author:

Dr. Lungdin Leima Cecilia

Postgraduate Students, Department

of Conservative Dentistry and

Endodontics, Divya Jyoti College of

Dental Sciences and Research,

Modinagar, Uttar Pradesh. India

\section{Emerging trends in endodontic irrigation}

\author{
Dr. Anil K Tomer, Dr. Lungdin Leima Cecilia, Dr. Hysum Mushtaq, Dr. Ayush \\ Tyagi, Dr. Shivendra Ahlawat, Dr. Tony Jose and Dr. Ayushi Khandelwal
}

DOI: https://doi.org/10.22271/oral.2021.v7.i1g.1170

\section{Abstract}

The main goal of endodontic treatment should be to focus on the predictable elimination of microorganisms from the root canal system. Irrigation has become a critical component of adequate root canal treatment. To obtain the goal of safe and effective irrigation methods this article review is to give a brief idea about irrigation devices and recent methods of irrigation. The irrigation process is often dismissed during endodontic treatment, must not be overlooked. It is one of the major keys of success for endodontic treatment.

Keywords: elastic modulus, flexural strength, provisional restorative materials

\section{Introduction}

It is a well-established fact that success of endodontic therapy depends on the main three factors:

a. Cleaning and shaping

b. Disinfection

c. Three-dimensional obturation of the root canal system.

As endodontists, our main goal should be to focus on the predictable elimination of microorganisms from the root canal system ${ }^{[1]}$. The success of the endodontic treatment is possible only with an understanding of the molecular biology of the pathogens, their structures, synergies, and weaknesses. Various methods have been developed in order to provide effective delivery. These systems might be divided into 2 broad categories, manual agitation techniques and machine-assisted agitation devices. Needles were used for manual agitation techniques and is still widely accepted by both general practitioners and endodontists. In this technique the dispensing of an irrigant into a canal through needles/cannulas of variable gauges, either passively or with agitation ${ }^{[1]}$.

The ultimate goal of endodontic treatment is to remove micro-organisms and their by products from the root canal space by using various antimicrobial agents to provide a environment free of micro-organisms. The present topic gives an insight into the various root canal disinfection, mainly irrigation and method and instruments of irrigation ${ }^{[2]}$.

\section{Quantec Irrigation System}

Complements rotary root canal instruments $\&$ is a portable self contained irrigation system. The peristaltic pump delivers irrigant via the handpiece as the root canal is being prepared by rotary file.

\section{Max-I-Probe}

The irrigant solution is then expressed very slowly until much of the chamber is filled.

A pumping action of the needle may enhance the 'mechanical flushing effect'.

'Perforated needles', that have perforation throughout the length are claimed to produce a much 


\section{Vibringe}

Vibringe (Vibringe BV, Amsterdam, The Netherlands) is a new sonic irrigation system that combines battery-driven vibrations $(9000 \mathrm{cpm})$ with manually operated irrigation of the root canal. Vibringe uses the traditional type of syringe/needle delivery but adds sonic vibration.

The Vibringe is the first endodontic sonic irrigation system that enables activation of the irrigation solution, acoustic streaming, in the root canal, in only one step.

Due to the turbulence caused by the activation of the irrigation solution, tissue residues and debris in the finest lateral canals and tubules are loosened and transported out of the canal easily. This results in a thorough debridement ${ }^{[3]}$.

\section{VATEA system}

The VATEA system is an irrigation device which is an integral part of Self Adjusting file rotary system (SAF). The VATEA system is a self-contained, fluid delivery unit intended to be attached to dental handpieces to deliver irrigation during endodontic procedures. During the endodontic treatment, irrigation solution is pumped from the VATEA's $400 \mathrm{ml}$ reservoir. The irrigant is delivered via a disposable silicone tube to the endodontic file. The flow of irrigant is toggled using a foot pedal. The operator can adjust the flow rate from $1-10 \mathrm{ml} / \mathrm{min}$ by using the $-/+$ push buttons located on the control panel ${ }^{[4]}$.

\section{Endovac}

Designed by Dr G. John Schoeffel. The system utilizes apical negative pressure through the practice's high volume suction system permitting thorough irrigation with high volumes of irrigation solution.

\section{Endo-Vac endodontic irrigation system}

The Endo Vac system consists of a Hi-Vac adapter assembly that connects to the high volume suction hose in the operatory at one end and has a ' $\mathrm{T}$ ' connector at the other end. The ' $\mathrm{T}$ ' connector permits a Master Delivery irrigation-suction tip with a disposable syringe filled with irrigation solution, and either a Macro-Cannula. or Micro Cannula is attached and used simultaneously with the Master Delivery tip during treatment ${ }^{[5]}$.

The plastic Macro Cannula is placed on a titanium handpiece, which is attached to tubing that connects to the ' $\mathrm{T}$ ' connector. This is used for coarse debris removal. The Micro Cannula is a metal suction tip available in either 25 or $31 \mathrm{~mm}$ lengths with 12 micro holes within the terminal $0.7 \mathrm{~mm}$ of the tip, permitting removal of particles that are 100 microns or smaller to the apical constricture. This tip fits into a metal finger-piece and is connected to the ' $T$ ' connector via tubing. The turbulent current forces developed by the Micro Cannula rapidly flows to the micro holes at the terminus which may be placed as close as $0.2 \mathrm{~mm}$ from the complete working length. The Master Delivery tip is employed to supply frequent and abundant irrigation because the orifices leaner canal (superficially) than the conventional needle are identified and explored. The advantage of the Master Delivery tip is that with one tip at the tooth's access, visibility isn't blocked and enormous volumes of irrigation solution are often utilized. The Macro Cannula is employed to get rid of coarse debris after instrumentation and is employed together with the Master Delivery tip, which delivers the irrigating solution. Apical negative pressure is made as irrigating solution is drawn down the canal towards the apex because it is expressed from the Master Delivery tip then is involved the
Macro- Cannula.

The Macro Cannula is taken to full working length and moved $2 \mathrm{~mm}$ with an "up and down" action every six seconds as each canal is flushed. This up and down action removes micro-gas bubbles formed during tissue hydrolysis. The endovac will add any canal configuration shaped a minimum of to a size 35 with a 0.04 taper or greater ${ }^{[6]}$.

\section{Endoactivator System}

The Endo Activator System (Advanced Endodontics) is comprised of a handpiece and variously sized polymer tips. Sonic activation has been shown to be an efficient method to enhance disinfection (Walmsley, Lumley and Laird, 1989; Pitt, 2005; Jensen et al., 1999). During use, the action of the Endo Activator tip frequently produces a cloud of debris which will be observed within a fluid-filled pulp chamber. The first function of the Endo Activator is to supply vigorous intracanal fluid agitation through acoustic streaming and cavitation. This hydrodynamic activation serves to enhance the penetration, circulation and flow of irrigant into the more inaccessible regions of the basis canal system (Guerisolo et al., 2002).

Preliminary research is showing the Endo Activator, utilizing polymer tips, may be a safe and effective method to both adapt and take away lime from a shaped canal. In the retreatment situation, clinical trials have shown that the Endo Activator System serves to break up and dislodge remnants of previously placed obturation materials ${ }^{[7]}$.

\section{Sonic handpiece}

The sonic handpiece is cordless, contra-angled, and ergonomic, and is used to drive the Endo Activator tips. The handpiece is operated by depressing the light-touch on/off switch that activates the strong and flexible polymer tips. The three-speed sonic motor switch provides options of 10,000, 6,000 and 2,000 cycles per minute (cpm). When the handpiece is activated, the power defaults to $10,000 \mathrm{cpm}$, which research has shown to be the recommended speed to maximize debridement and disruption of the smear layer and biofilm (Caron, 2007; Gulabivala, 2006) ${ }^{[8]}$.

\section{Passive Ultrasonic Irrigation}

Ultrasonically activated files have the potential to prepare and debride root canals mechanically. The files are driven to oscillate at ultrasonic frequencies of $25-30 \mathrm{kHz}$ that are beyond the limit of human hearing. The files operate in a transverse vibration, setting up a characteristic pattern of nodes and anti-nodes along their length (Walmsley 1987, Walmsley \& Williams 1989). Unfortunately, it proved to be difficult to control the cutting of dentine during ultrasonic preparation, with the result that it is impossible to control the shape of the prepared root canal and apical perforations and irregular shapes were produced (Stock 1991, Lumley et al. 1992) ${ }^{[9]}$.

\section{Rinsendo}

The RinsEndo system (Durr Dental Co) is based on a pressure-suction mechanism with approximately 100 cycles per minute. The Rinsendo is an instrument for the hydrodynamic rinsing and flushing of root canals. It serves to deliver an active ingredient in a pulsating manner directly into the root canal via a special cannula. With the Rinsendo connected to the turbine coupling compressed air enters the Rinsendo via the coupling adapter and is applied to the Impulse Generator when the foot pedal of the treatment unit is 
pressed. The Impulse Generator acts as a pneumatic regulator driving the piston within the handpiece producing a pulsating rinse-suction cycle at the Rinsendo Cannula ${ }^{[10]}$.

\section{Photodynamic therapy}

Photoactivated disinfection (PAD) has been recommended as an adjunctive procedure to kill residual bacteria in the root canal system after standard endodontic debridement. It involves the use of a photosensitizer (e.g. methylene blue dye) that is activated by light in the presence of oxygen. Photosensitizer binds to bacterial membrane surface and enters into cytoplasm. When exposed to the light of a specific wavelength, a photosensitizer can react with either oxygen or other biomolecules to create free radicals, resulting in cell death. PAD has been claimed to target microorganisms with no collateral damage to human cells and tissues ${ }^{[11]}$.

\section{Gentle Wave system}

A multisonic ultra cleaning system, the Gentle Wave (GW) system (Sonendo Inc, Laguna Hills, CA), has recently been developed for cleaning of the root canal system. The GW system was designed to deliver a broad spectrum of sound waves within the irrigant to effectively clean the root canal system with minimal or no instrumentation. It has been reported that the GW system can thoroughly clean the root canal system even in the apical third. The system disperses fluids from the tip of the handpiece into the pulp chamber, causing cavitation effect. A recent study on the GW system showed it had eight times faster tissue dissolution rate compared to other irrigation systems including ultrasonic irrigation, EndoVac and needle irrigation ${ }^{[12]}$.

\section{Ozone based Delivery System}

Ozone is a triatomic molecule consisting of three oxygen atoms. It is applied to oral tissues in the forms of ozonated water, ozonated olive oil and oxygen/ozone gas. It is unstable and dissociates readily back into oxygen, thus liberating socalled singlet oxygen $(\mathrm{O} 1)$, which is a strong oxidizing agent which further impose the deleterious effect on microorganisms. Various delivery systems available for endodontic irrigation like Neo Ozone Water-S unit, HealOzone (Kavo) unit, the OzoTop unit ${ }^{[13]}$.

\section{LASERS}

The applications of lasers are abundant, and the count still goes on as more and more research has been directed towards maximizing benefits. With so many applications to its credit, lasers will define a new future for endodontics ${ }^{[14]}$.

According to Gutknecht et al., Ho -YAG shows excellent antibacterial efficacy against E- Faecalis while $\mathrm{CO}_{2}$ laser shows mixed response. Takeda et al. concluded that $\mathrm{Co}_{2}$ laser removed and melted the smear layer on instrumented canal walls while Er-YAG laser is most effective in removing the smear layer ${ }^{[20]}$.

With PIPS, the apex can be reached without the need to negotiate the tip close to the apex. Correspondingly, this would allow a less-invasive preparation using an ISO size \#20/.06 file, according to the method described. Irrigation with chelating agents following the current conventional instrumentation procedure requires more time to initiate a satisfactory debridement (EDTA placed passively into the prepared root canal) ${ }^{[15]}$.

The PIPS technique resulted in pronounced smear layer removal when used together with EDTA and at the settings outlined ${ }^{[16]}$.
Published material on endodontic techniques using the Er: YAG laser provides differing operating parameters. These authors recommend the use of higher average power (1.125$1.5 \mathrm{~W})$ delivered through end-firing laser tips. Additionally, these tips need to be placed $1-2 \mathrm{~mm}$ from the apex ${ }^{[19]}$.

\section{Light Activated Disinfection (LAD)}

It is a photodynamic antimicrobial chemotherapy. It has a photosensitiser (toluidine blue dye, methylene blue dye etc). The canal is then filled with photosensitiser and then illuminated with a light source (laser, white light, red light or a light eliminating diode. Light activated disinfection (LAD), also termed photodynamic therapy (PDT) or photoactivated disinfection, is based on three elements: The photosensitizer (a non-toxic dye), the target cell or tissue, and a low-intensity light source with a specific wave length. On sensitization of the tissue with the photosensitizer (PS) and subsequent light exposure, singlet oxygen and oxygen radicals are released, resulting in the rupture of microbial cells. Internalization of the PS results in further damage to the microbial cellular biomolecules. Since the introduction of LAD in endodontics, numerous studies have been carried out to demonstrate the effect of different photosensitizers on the root canal microbiota ${ }^{[17]}$.

\section{Conclusion}

Irrigation has become a critical component of adequate root canal treatment. In an effort to further improve the effectiveness of irrigation various methods have been devised to augment the irrigation process. Applying mechanical agitation or activating the irrigants has been shown to improve the cleanliness of the canal. Various modalities of activation of irrigant are available. Mechanically agitating an irrigant can be done by sonic or ultrasonic activation. Using sonic or ultrasonic activation converts electric energy into waves with certain frequencies. This energy produces a rapid movement of fluid in a circular motion around the vibrating instrument. This rapid movement is called acoustic streaming and occurs inside the canal when activating irrigant. The effect of acoustic streaming is to cause a directional flow of the irrigant to the coronal part of the root canal and is propagated by the node formation along the length of the instrument being activated. The irrigation process is often dismissed during endodontic treatment, must not be overlooked. It is one of the major keys of success for endodontic treatment. The irrigation usually reduced to a needle on the tray must be systematically evaluated in order to become an endodontic entity having a precise chronology and codification $^{[18]}$.

\section{Reference}

1. Grossman LI. Origin of microorganisms in traumatized, pulpless, sound teeth. J Dent Res 1967;46:551-553.

2. Siqueira JF Jr, Rocas IN, Santos SR, Lima KC, Magalhaes FA, de Uzeda M. Efficacy of instrumentation techniques and irrigation regimens in reducing the bacterial population within root canals. J Endod 2002;28:181-4.

3. Bystrom A, Sundqvist G. Bacteriologic evaluation of the efficacy of mechanical root canal instrumentation in endodontic therapy. Scand J Dent Res 1981; 89:321-8.

4. Nielsen BA, Baumgartner JC. Comparison of the Endo Vac System to needle irrigation of root canals. J Endod 2007;33:1-5.

5. Pouch D, Bohne W, Enkel B. et al. Comparative Safety 
of Various Intracanal Irrigation Systems. J Endod 2007;35:545-549.

6. Hockett JL et al. Antimicrobial efficacy of two irrigation techniques in tapered and nontapered canal preperations:An in vitro study. Journal of Endodontics 2008;34(11):1374-1377.

7. Cameron Townsend, James Maki. An In Vitro Comparison of New Irrigation and Agitation to Ultrasonic Agitation in Removing Bacteria from a Simulated Root Canal. J Endod 2009;35:1040-1043

8. Jeen-Nee Lui, Hong-Guan Kuah, Nah-Nah Chen. Effect of EDTA with and without surfactants or ultrasonics on removal of smear layer. Journal of Endodontics 2007;33(4):472-475

9. Petriria RRB, Letricizia Souza C. Efficacy of ultrasonic cleaning. Journal of Endodontics 1980;6:740-3.

10. Bon Verhaagen Endosonic root canal file oscillations: an in vitro evaluation. Journal of Endodontics Publisher: Elsevier Ltd 2010;36(5):880-883.

11. Cesar de Gregorio, Roberto Estevez. Effect of EDTA, Sonic, and Ultrasonic Activation on the Penetration of Sodium Hypochlorite into Simulated Lateral Canals: An In Vitro Study. Journal of Endodontics 2009;35(6):891895.

12. Roeland JG. De Moor, Maarten Meire. Efficacy of Ultrasonic versus Laser-activated Irrigation to Remove Artificially Placed Dentin Debris Plugs. J Endod 2010;36:1580-1583

13. Konietschk Graham, Khan N, Francois N. Comparison of the Vibringe System With Syringe and Passive Ultrasonic Irrigation in Removing Debris From Simulated Root Canal Irregularities. J Endod 2010, 1-4

14. Rodig T, Sedghi M, Konietschke F. Efficacy of syringe irrigation, Rins Endo and passive ultrasonic irrigation in removing debris from irregularities in root canals with different apical sizes. Int Endod J 2010;43(7):581-9.

15. Rodrigo T. Minin Bozkurt Comparison of the Vibringe System With Syringe and Passive Ultrasonic Irrigation in Removing Debris From Simulated Root Canal Irregularities. J Endod 2010, 1-4.

16. Carlos Heilborn, Kai Reynolds. Cleaning efficacy of an apical negative-pressure irrigation system at different exposure times. Quintessence international Berlin Germany 2010;41(9):759-767.

17. Enrico DiVito. DDS, Scottsdale, Arizona, United States; Mark P. Colonna The Photoacoustic Efficacy of an Er:YAG Laser with Radial and Stripped Tips on Root Canal Dentin Walls: An SEM Evaluation J Laser Dent 2011;19(1):156-161

18. Manuele Mancini, DDS, ${ }^{*}$ Loredana Cerroni, DDS, $\uparrow$ Lorenzo Iorio, DDS,* Smear Layer Removal and Canal Cleanliness Using Different Irrigation Systems (EndoActivator, EndoVac, and Passive Ultrasonic Irrigation) JOE 2013;39:1456-1450

19. Ricardo Macedo DMD, MSc,* Bram Verhaagen MSc, $\mathrm{PhD}, \uparrow$ David Fernandez Rivas MSc, PhD. Cavitation Measurement during Sonic and Ultrasonic Activated Irrigation JOEVolume 2014;40(4):580-583.

20. Deenadayalan Elumalai, Dr. Ashok Kumar, Dr. Rajendra Tewari K, Dr. Surendra Mishra K. Newer Endodontic irrigation devices: An update IOSR Journal of Dental and Medical Sciences (IOSR-JDMS). Ver. V 2014;13(6):0408 . 